response. Tactual cues are also sufficient to control a descent of 2 in. in the absence of shallow visual cues, when they become avallable through lengthening of the orientation response. These findings indicate that during the appetitive phase of descent behavior (the orientation response) both visual and tactual cue-seeking processes are operative. The tactual process is to some degree independent of visual influences.

The much greater tactual discrimination shown by the 17 older Ss in the tactual condition was unexpected. In addition to age, these Ss differed from the other 16 in having been housed for approximately 9 months in standard laboratory group cages. It is possible that such an environment reinforced reliance upon tactual cues. Among the 65- to 75-day-old Ss, visual cues were the primary determinant of descent on early trials. Thus, only three Ss in the visual-unpatterned group left the $2-2$ platform on the first day, while all but one $S$ in the visual-pattemed group descended. Tactual cue-seeking was effective primarily on later trials.
The deep orientation response, and subsequent descent from a 2 -in. height, is thus controlled by at least three factors: prevailing visual cues, appetitive tactual cue-seeking, and previous reinforcement. After reinforcement has occurred, as when shallow visual cues are obtained, the deep orientation response may be considered confirmatory rather than appetitive.

\section{BITTERMAN, M. E., \& WODINSKY, J.} Simultaneous and successive discrimination. Psychological Review, 1953, 60, 371-376.

THIESSEN, D. D., LINDZEY, G., BLUM, S., TUCKER, A., \& FRIEND, H. C. Visual behavior of the Mongolian gerbil (Meriones unguiculatus). Psychonomic Science, 1968, 11, 23-24.

WALK, R. D., \& GIBSON, E. J. A comparative and analytical study of visual depth perception. Psychological Monographs, 1961, 75(Whole No. 519), 1.44.

\section{NOTES}

1. This work was supported by NIMH Grant No. MH 14076-02 and by NIMH Research Development Award MH 11, 174-02 to D. D. Thiessen.

2. A detailed account of the AOV is available upon request.

\title{
Chlorpromazine slows decay of visual short-term memory'
}

\author{
GEORGE C. STONE, ENOCH CALLAWAY \\ III, REESE T. JONES, and TOM \\ GENTRY, L Langley Porter Neuro- \\ psychiatric Institute, San Francisco, Calif. \\ 94122
}

The effects of chlorpromazine, scopolamine, and pentobarbital on the visual short-term memory trace were studied using Sperling's method. Ss were classified as introverts or extraverts with the Maudsley Test, but this variable had no significant effect. Analysis of variance showed a significant difference among the drug treatments $(p<.05)$. The mean numbers of correct responses for scopolamine, pentobarbital, and placebo, among which there was no significant difference, were pooled and found to differ significantly from the chlorpromazine mean $(p<.01)$. It was concluded that chlorpromazine improved performance either by filtering poststimulus "noise" or by delaying the encoding process for the visual STM trace, thereby making the information available longer.

Sperling's (1960) experiments on visual short-term memory offer an approach to the study of drugs on this initial phase of visual information processing. Chlorpromazine, scopolamine, and pentobarbital all share sedative actions, while chlorpromazine and scopolamine also share anticholinergic action. Yet the drugs are quite dissimilar in other respects-for example, only chlorpromazine is effective in the treatment of schizophrenia. We have therefore undertaken to study the effects of chlorpromazine, scopolamine, and pentobarbital on the decay of visual STM using the Sperling design.

The effects of these drugs on the performance of introverts and extraverts was also examined, in light of the contention by Eysenck (1957) that introverts are less neurally inhibited than extraverts.

\section{METHOD}

Subjects were 40 male medical and dental students, who were paid for their participation in the experiment. Ss were selected from among 65 prospective $S s$ on the basis of the 20 highest and 20 lowest scores on the Extraversion scale of the Maudsley Personality Inventory. Ss were divided into four drug groups of 10, five introverts and five extraverts to a group. Ss in each group received one of the following: chlorpromazine $(50 \mathrm{mg})$, scopolamine $(\mathrm{C} .6 \mathrm{mg})$, pentobarbital $(100 \mathrm{mg})$, or placebo. Drugs were administered in identical capsules and were taken simultaneously by all Ss.

While the drugs were taking effect, Ss filled out information questionnaires and were familiarized with the experimental procedures to be given them. The experiment proper began $45 \mathrm{~min}$ after ingestion of the drugs.

The Ss were seated in the auditorium of Langley Porter Neuropsychiatric Institute at a distance of 23 to $31 \mathrm{ft}$ from a projection screen. Seating position was counterbalanced for drugs and temperaments. Ss were presented with nine-letter ( 3 by 3 ) matrices flashed onto the screen for $1 / 15 \mathrm{sec}$, timed by a Prontor-Press shutter (Ledex, Inc., Dayton, Ohio). Only the 20 consonants were used, to minimize the possibility of the letters' being interpreted as words. Auditory signals were presented by a speaker system at three frequencies $(2500$, $650,250 \mathrm{~Hz}$ ) to indicate which of the three rows of three letters the Ss were to report on the answer sheets provided. The following six time intervals were used, expressed in milliseconds, from termination of flash to onset of tone: $-500,0,100,200,500$, 1000. A PDP-7 computer was programmed to initiate the flash and tone and to set the length of the tone $(500 \mathrm{msec})$.

Subjects were familiarized with the procedure in 24 practice trials. Then, three blocks of 18 presentations were run, with each of the six delays paired with each of the three tones in every block. Thus, each $\mathrm{S}$ had an opportunity to identify 27 letters at each delay. Ss were instructed to guess if they were not sure of the correct let ters and were told to guess different letters, not simply to write XXX. Trials were run approximately every 5 to $10 \mathrm{sec}$, with a short break between blocks. The experiment proper lasted about $10 \mathrm{~min}$.

\section{RESULTS}

The mean number of letters identified by introverts (13.5) and extraverts (14.8) did not differ significantly overall $(\mathrm{F}=2.23$, $\mathrm{df}=1 / 32, \mathrm{p}>.05$ ). The interaction of introversion-extraversion with drugs was not significant either, so Ss were pooled into a single group for each drug.

Figure 1 shows the mean number of correct responses plotted against delay for each treatment. The number of letters from the correct row but reported in the wrong position was found not to exceed chance; therefore, only letters from the indicated row recorded in the proper position were scored as correct responses.

Three-way analysis of variance with repeated measures showed a significant difference among the drug treatments 


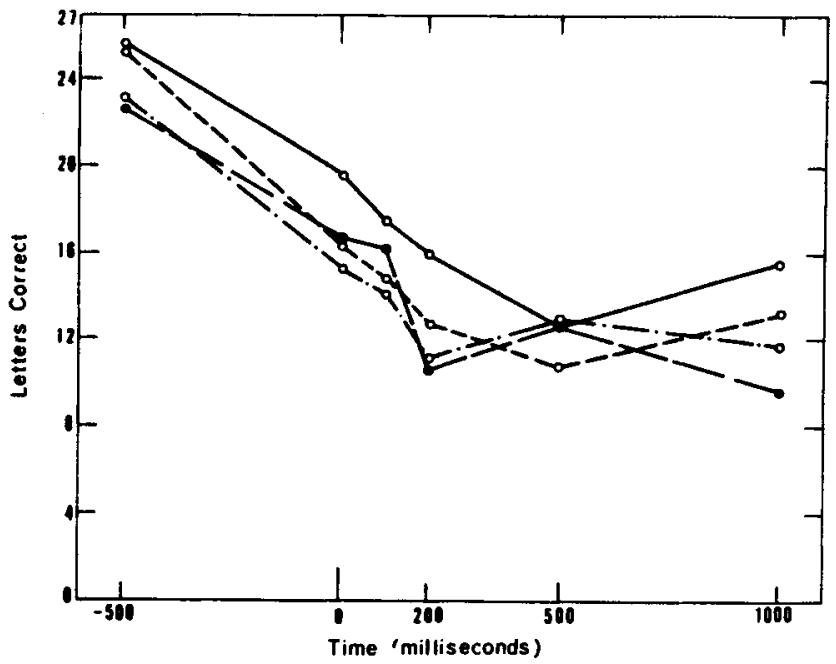

Fig. 1. Mean number of correct responses made by the four drug treatment groups as a function of delay between stimulus and reporting cue. $0-0$, chlorpromazine; $\bullet-$, scopolamine; o-- - o, pentobarbital; 0- - -o, placebo.

$(F=3.156, d f=3 / 32, p<.05)$. Treatment by Delay interactions were not significant $(F=1.022, \mathrm{df}=12 / 128, \mathrm{p}>.05)$. Scopolamine, pentobarbital, and placebo did not appear to differ, and a separate analysis of variance showed this to be the case $(F<1.0$, $\mathrm{df}=2 / 24, \mathrm{p}>.05$ ). These three treatments were therefore pooled and tested against the mean for chlorpromazine. This difference was found to be significant $(F=8.371$, $\mathrm{df}=1 / 38, \quad p<.01)$. It was therefore concluded that chlorpromazine improved Ss' performance on the task. quent stimuli have a reduced effect(Killam, 1968). In this case, chlorpromazine would depress interfering poststimulus "noise" and allow retrieval of data from visual STM for a longer period. Finally, chlorpromazine delays the initiation of motor action; for example, it suppresses avoidance behavior without reducing escape behavior (Cook \& Catania, 1964). If the removal of visual STM trace were a positive action, and chlorpromazine produced a delay of that action, then again chlorpromazine would protect the STM trace.

The data allow us to reject the first altemative. Further research is needed to permit a choice between the second and third altematives.

\section{REFERENCES}

COOK, L., \& CATANIA, A. C. Effects of drugs on avoidance and escape behavior. Federation Proceedings, 1964, 23, 4, 818-835.

EYSENCK, H. J. The dynamics of anxiety and hysteria. New York: Praeger, 1957.

KILLAM, E. K. Pharmacology of the reticular formation. In D. H. Efron (Ed.), Psychopharmacology: A review of progress 1957 1967. Public Health Service Publication No. 1836. Washington, D.C.: U.S. Government Printing Office, 1968. Pp. 411-445.

Three alternative actions seemed plausible before the data were analyzed. First, chlorpromazine enhances habituation (Wilson \& Glotfelty, 1958). If habituation is an inhibitory process related to the decay (inhibition) of the visual STM trace, then chlorpromazine should speed STM trace decay. Second, chlorpromazine increases filtering-the first of a series of stimuli acts with full force, but the activating effect of this stimulus on the RF is enhanced by chlorpromazine with the result that subse-
SPERLING, $G$. The information available in brief visual presentations. Psychological Monographs, 1960, 74, (Whole No. 498).

WILSON, W. P., \& GLOTFELTY, J. S. Effect of intravenous promazine on arousal responses in man. Diseases of the Nervous System, 1958, 19 , 307.309.

\section{NOTE}

1. The last mentioned author is at Kalamazoo College, Kalamazoo, Mich. 49001. This work was supported by GRSG Grants FR-05550, MH 32904, and NONR-2931 (00). 